\title{
THE SOCIAL CONSEQUENCES OF HIGH POPULATION DENSITY*
}

\author{
Halliman H. Winsborough†
}

The man who participates in decisions about urban affairs today seems a most unreasonably imposed-upon fellow. Not only is he called upon to be comfortable in both of C. P. Snow's two cultures (on the one hand considering engineering problems and on the other choosing among competing notions of urban esthetics), but he is frequently asked to show some familiarity with a third minor but lustily growing culture: that of the social sciences. To walk in the elegant and orderly garden of natural science and to trace subtle paths in search of taste no doubt offer some pleasure. To hack one's way through the tangled thicket of the social sciences, however, must frequently seem an imposition-especially so if one's major business lies elsewhere.

The motive of this paper is to offer some aid and comfort to the person who looks in the social sciences for assistance in making choices in urban planning.

Let us begin by arguing that most work in the social sciences can be divided into two kinds. The distinction between the two depends on taste and judgment as to how things in the social world are to be explained. One group of social scientists, who may be designated behavioralists, explain things in terms of the actions which individuals take. From the point of view of the behavioralists, if we know enough about the causes, motives for, and constraints upon individual action we can account for the behavior of groups of people, or even of whole cities, by a process of aggregation.

The second group, whom we will call the structuralists, argue that the very collection of persons into groups provides possibilities and produces characteristics which are not to be derived from a summation of the characteristics of individuals. For example, the law of a country is not easily explained in terms of the motives and actions of the persons presently resident there.

Each of these points of view can be made persuasively by their adherents. Each has been productive of exciting research and discovery. When each is on its home ground all is well. However, when both points of view seem to apply at the same time, or when one tries to take both factors into account at once, the problem becomes complex and the dogmatic statements issuing from both camps become

* This paper is based on research supported by a grant from the Duke University Council on Rescarch. Some of the computations involved were carried out in the Duke University Computing Laboratory which is supported, in part, by the National Science Foundation.

+ A.B. 1952, M.A. 1959, Ph.D. 1961, University of Chicago. Assistant Professor of Sociology and Associate Director, Population Studies Program, Duke University. Author [with Otis Dudlcy Duncan and others], Metroporis and Region (1960). 
vociferous. It is at this juncture that one must keep one's head and, recognizing the limits as well as the extent of knowledge, try to assess the balance of effects in exercising decision.

Since all of the foregoing no doubt seems fairly abstracted from the everyday decision in urban affairs, let us consider an extended example. A not uncommori problem in urban planning concerns the proper level of population density for which to plan. Certainly various levels of density have various costs and various advantages: Supposing that an intrepid man began to search the literature in sociology in hopes of finding some guidance about the nature of these costs and advantages: what might he find?

He would discover that two somewhat separate traditions in sociology argue that the level of population density in a human society has important social consequences. Each tradition is based on the writings of one of the founding fathers of modern sociology and each has fairly vigorous present-day adherents. The consequences presumed by these two traditions are, however, rather different. On the one hand, the structuralists, following a Durkheimian point of view, see high population density, along with high population size, as a prerequisite for the development of division of labor. ${ }^{1}$ On the other hand, behaviorally-oriented followers of Simmel stress the psychological-and even physiological-strain involved in the frequent stimulation and interaction concomitant with dense living. ${ }^{2}$

The Durkheimian position is succinctly summarized by Halbwachs as follows: ${ }^{3}$

In reality, the division of labor results from the expansion of human groups and from the increase in their density. These are necessary conditions, (I) for the appearance and development ... of a great variety of aptitudes and also of needs; (2) for bringing aptitudes and needs together in reciprocal stimulation ... and (3) for establishing increasingly precise adaptation between the techniques of the more and more specialized producers and the needs of the more and and more diversified consumers.

This point of view has received theoretical and empirical elaboration in the development of central place theory. This theory argues that a certain number of consumers are necessary within a given radius of a center for the support of a specific good or service." Whether a specific good or service becomes a central one, then, depends upon the population density of the area in question, that is, upon whether it will find a sufficient number of consumers within its range. Some

\footnotetext{
${ }^{1}$ Emile Durkheim, The Division of Labor in Society 256-82 (George Simpson transl. 1960).

${ }^{2}$ Simmel, The Metropolis and Mental Life, in PAUL K. Hatr \& Albert J. Reiss (EDs.), Cities and SocIETy 635-47 (1957).

${ }^{3}$ Maurice Halbwachs, Population and Society 173 (Otis Dudley Duncan \& Harold W. Pfauts transl., I960).

A concise presentation of central place theory is given in Ullman, $A$ Theory of Location for Cities, in HATT \& ReIss, op. cit. stupra note 2, at 227-36. For a more lengthy treatment, see August Losch, The Economics of Location (William H. Woglam \& Wolfgang F. Stolper transl., 1954). Additional citations can be found in Brian J. L. Berry \& Allen Pred, Central Place Studies: A Bibljography of Theory and Applications (I96I).
} 
recent developments in this theory suggest it may apply to the distribution of services in the city as well as the distribution of cities in space."

The Simmelian point of view has also received recent empirical support-a good deal of it from studies of animal behavior. In an attempt to investigate the relationship between animal behavior and population characteristics in a species living in the wild, Calhoun confined a group of wild rats to a quarter-acre enclosure. ${ }^{b} \mathrm{He}$ provided an abundance of food and relative freedom from predators. Population did not rise as expected because of an increase in infant mortality. This increase, Calhoun held, came about because stress from social interaction led to disruption of maternal behavior. Pursuing this hypothesis under laboratory conditions, Calhoun permitted caged populations of experimental rats to develop about twice the density which seemed to provide only moderate stress. ${ }^{7}$ His results were dramatic. Many females became unable to carry pregnancy to full term. Many of those who did were unable to survive the delivery. Of those who survived, many subsequently fell so short in their maternal functions that infant mortality ran as high as ninety-six per cent in some experimental groups.

Males, too, exhibited strange behavior, ranging from sexual deviation to cannibalism, and from frenetic overactivity to pathological withdrawal.

Calhoun holds that these disturbances in behavior are the result of the stress from social interaction. Other investigators have found a direct relationship between density and adult animal mortality. Deevey cites some literature in support of this relationship and offers a physiological explanation of the relationship between the stimulation due to increased interaction and mortality. ${ }^{8}$

In summary, then, there is considerable evidence supporting both consequences of high levels of population density. Given the weight of the evidence it would seem unwise to simply disregard one or another of these effects. The problem becomes one of assessing the outcome of their joint influence. In a paper in which he speculates on the combination of these effects on human populations, Calhoun conceptualizes the problem as follows. ${ }^{9}$ He associates the level of density which maximizes the division of labor with what he calls the economic climax state of the society. That level of density which minimizes psychological and physiological stress from interaction he associates with the social climax state. Of these he says: ${ }^{10}$

It is logical to assume that the social climax can be achieved at a lower density than the economic climax. Thus the population characteristic of the economic climax

\footnotetext{
${ }^{-}$Carol, The Hierarchy of Central Functions Within the City, 50 ANNALs of THE Ass'N of AM. Geoo. RAPHERs $4 \mathrm{Ig}$ (1960). Some additional pertinent discussion is found in Ludlow, Urban Densities and Their Costs: An Exploration Into the Economics of Population Densities and Urban Patterns, in Coleman Woodbury (Ed.), Urban Redevelopment: Problems and Practices i02-20 (I953).

${ }^{\circ}$ Calhoun, A Method for Self-Control of Population Growth Among Mammals Living in the Wild, IO9 SCIENCE 92 (r949).

${ }^{7}$ Calhoun, Population Density and Social Pathology, Scientific American, Feb. 1962, pp. 139-48.

${ }^{8}$ Deevy, The Hare and the Haruspex: A Cautionary Tale, 40 YALE REv. I61 (I959).

${ }^{\circ}$ Calhoun, Social Welfare As a Variable in Population Dynamics, 22 Cold Spring Harbor Symposin on Quantitative Biolocy 339-56 (I957).

${ }^{10}$ Id. at 355 .
} 
community may serve as a yardstick of value judgment at what level the population should stabilize. Since this level is likely to be attained in the United States within the next 50 or roo years, any individuals or groups who encourage population growth at a rate likely to make this level to be exceeded, draw upon themselves the onus of con. tributing to the difficulties of achieving the climax social community.

Although Calhoun's statement may well be correct, it seems an oversimplification of a complex problem. First, it seems likely that, as with the problem of optimum city size, the optimum level of density, taking into account both stress and the division of labor, may vary with the characteristic to be optimized. ${ }^{\mathbf{1 1}}$ Further, there remains the question of the relative magnitude of the effects of stress and the division of labor upon a characteristic to be optimized. Given that the human animal is subject to the psychological and physiological stress due to interaction documented for other animals, it remains a question, for instance, whether easier access to medical facilities in a dense population may not significantly ameliorate effects of stress on adult human mortality.

By the time our urban decision-maker had reached this point in his search of the sociological literature, he would no doubt feel that his patience as well as the accumulated knowledge was exhausted. Not a great deal of specific information about the problem of the affects of various density levels within the urban community has been provided. In fact, about all that has been accomplished is to suggest that the decision about the level of population density is an important one.

Given all the foregoing information, how should a man try to influence the decision process with respect to population density levels? Certainly the behavioralists' findings are impressive. But in many circumstances the pressure of costs will argue for higher density. Since the latter argument has a kind of life of its own, perhaps one should use his influence to argue for lower density presuming that the net result will approximate Calhoun's social climax state.

Would such a decision be justified? Would further research on the problem make this decision strategy wrong? I was curious enough about these questions to try to carry the research process along another step in the hope of being able to make some pertinent assessment.

To begin this investigation, I returned to the original Simmelian topic of people living in the city. I investigated the relationships between population density and a series of variables similar to or suggested by Calhoun's work as they occurred in the seventy-five Community Areas in the city of Chicago. These Community Areas are a partitioning of the land area of the city which was accomplished some years ago and are convenient for this analysis because they demonstrate a considerable variability in population density.

Five variables suggested by Calhoun's writings were readily available. ${ }^{12}$ They

${ }^{11}$ Duncan, Optimum Size of Cities, in HaTr \& REISs, op. cit. supra note 2, at 759-72.

${ }^{13}$ Data are taken from Philip M. Hauser \& Evelyn M. Kitagawa (Eds.), Local Communitx Fact Book fOR ChICAgo, I950 (I953). 
are the infant death rate, an over-all death rate which has been adjusted for differences between areas in age composition, a tuberculosis rate, an overall public assistance rate adjusted for differences in age composition, and a measure of the rate of public assistance to persons under eighteen years old. Parsonian correlation was used as a measure of the association between each of these variables and the level of population density over the community areas. These correlations are given in the first column of table one. All but one of the variables showed a positive correlation with population density. That is, the higher the density the higher the rates. The exception to this rule was the overall death rate which showed no appreciable association with density.

These findings certainly suggest that increased density has a deleterious affect on the population. To assume that this affect is caused by increased stress is, however, a long logical leap. In fact, only a moderate acquaintance with cities would suggest an alternative explanation. People of lower socioeconomic status-people more likely, irrespective of density, to score higher on all of the rates investigatedtend to live closer to the center of the city than do persons of higher socioeconomic status. Further, population density declines in a regular way as one moves outward from the city center. These facts suggest that socioeconomic status may be confounding the relationships which we wish to investigate. Another variable which may confound the relationships is quality of housing, which also has association with density and with each of the rates. Finally, any affects of stress which may be present are confounded because the number of in-migrants to each area is likely to be different.

In order to avoid these confounding variables, then, one would like to investigate the associations between population density and each of the five rates "controlling" for socioeconomic status, quality of housing, and migration. ${ }^{13}$ We have chosen to accomplish this by partial correlation, a fairly satisfactory technique which allows one to approach the "control" of the classical experiment. A list of the variables "partialed out" can be found in note ${ }^{a}-2$ of table one. The values of the partial correlations are given in column two of that table.

Removing the effects of socioeconomic status, quality of housing, and migration changes the pattern of the findings considerably. The overall death rate, which had originally shown no relationship with density, changed to a strong negative association: the higher the density, the lower the rate. The infant mortality rate, however, which had originally been positively associated with density, continued virtually unchanged in its association with density. Thus, after control, one mortality rate is

\footnotetext{
${ }^{18}$ It may be noted that one of the variables held constant, per cent of dwelling units having more than $\mathbf{r} .5 \mathrm{I}$ persons per room, is related to the number of persons per room, a component of total density. This aspect of density was treated separately because of some thought that its effects might be different from those of total density. The finding was, however, that the pattern of partial correlations was similar to that for total density except that all correlations except for those for assistance to juveniles were smaller and that public assistance was signed positively and assistance to juveniles was signed negatively.
} 
TABLE I

Zrro-Order and Partial Correlation of Gross Population Density and Stated Dependent Variagle; Community Areas, City of Chicago, i950

\begin{tabular}{|c|c|c|}
\hline Dependent Variable & $-\frac{\text { Varial }}{\mathrm{I}}$ & $\begin{array}{l}\text { Constant }^{\mathrm{a}} \\
-\frac{-}{2}\end{array}$ \\
\hline Infants deaths per yoo live births & $.32 * *$ & $\cdot 33^{* * *}$ \\
\hline Age standardized deaths per rooo persons &.$x_{4}$ & $-.62 * *$ \\
\hline $\begin{array}{l}\text { Tuberculosis cases per 10,000 persons is } \\
\text { years and older }\end{array}$ & $.20 *$ & $-.67^{* *}$ \\
\hline $\begin{array}{l}\text { Age standardized public assistance per } \\
\text { rooo persons }\end{array}$ & $.37^{* * *}$ & $-.39^{* *}$ \\
\hline $\begin{array}{l}\text { Quintile ranking of public assistance to } \\
\text { persons under } 18 \text { per I000 persons un- } \\
\text { der I8 }\end{array}$ & $.45^{* * 2}$ &.$x_{4}$ \\
\hline
\end{tabular}

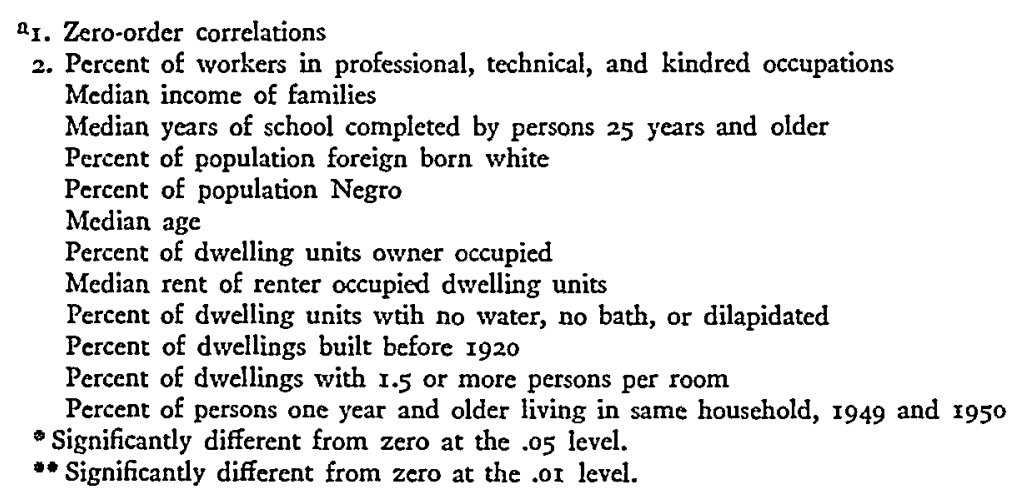

in the direction predicted by the behavioralists and another in the direction predicted by the structuralist argument. The tuberculosis rate, which originally had a positive association with density, becomes, under control, strong and negative. This is a very odd finding, suggesting that, ceteris paribus, high density leads to low tuberculosis rates. Both public assistance measures were originally positively associated with density. After control, each has changed but in a somewhat different way. Overall public assistance becomes negatively associated with density while assistance to persons under eighteen years of age demonstrates no appreciable association.

After control for the three confounding factors, then, we have a fairly mixed bag. One rate shows the positive association with density predicted by the behavioralists' argument. ${ }^{14}$ Three show the negative association predicted by the structuralist argument. The final rate shows no association.

14 An interesting methodological point arises in using the data in this fashion. At first blush, it 
Perhaps the only order that we can bring to these heterogeneous findings is to suggest that the affects of density on the young seem to be different from the affects on the adult population. The findings certainly add weight to the previously stated guess that the optimum level of density varies with the thing to be optimized.

Before proceeding further let me insert the scholar's usual note of caution. Clearly the foregoing findings are rather tentative. Inferences from high order partial correlations is a notoriously tricky game. I have investigated the affects of density as it varies within only one city. Clearly there might be different outcomes in other cities, and variation between cities might produce still other outcomes. Despite these demurs, the results of the analysis are strong and curious enough to warrant further investigation.

Where does all this leave the man who must arrive at some policy with respect to urban planning? Not very far along, I expect. The original strategy proposed before the statistical analysis seems to fare reasonably well. It might be modified only by suggesting that lower density should be accompanied with a diminution of the catchment area for medical facilities.

If all the foregoing is taken as a cautionary tale, I suppose its moral is to take with a grain of salt dogmatic claims by either behavioralists or structuralists when good sense or the pressure of realistic constraints suggests that variables from the opposite camp should be taken into consideration. No doubt some day the social sciences will offer a larger fund of demonstrated principles to aid the decisionmaker. But it will certainly be a long time before solutions to problems in urban affairs can be spewed forth from a computer without the inclusion of a factor of good judgment.

appears that we are commiting the "fallacy of ecological correlation" in investigating a phenomena which occurs at the individual level using aggregated data for eensus tracts. It seems to us, however, that our problem is rather different from that usually discussed in terms of the classical fallacy. Our problem is not to assess the existence of an individual effect of density on stress. Such an assessment can be performed with considerably greater elegance and precision in an experiment. In the main we find Calhoun's demonstration fairly compelling as to the existence of the effect. Rather, it is our aim to investigate the balance of effects, individual and aggregative, which derive from the variation in density. Thus we argue that, rather than being fallacious, an ccological correlation is a convenicnt device to investigate the balance of effects in the aggregate. 